\title{
An Evaluation of the Seismic Hazard Prior to the Extraction of a Shaft Pillar at Kloof Gold Mine
}

\author{
G.D. Mungur KLOOF - A Division of Gold Fields International Mining South Africa (Pty) Ltd
}

Kloof Gold Mine is in the planning phase of extracting the Main Shaft Pillar on the Ventersdorp Contact Reef. Situated at an average depth of $2500 \mathrm{~m}$ below surface, this shaft pillar hosts 1 surface and 3 sub-shafts. The surface shaft terminates approximately $40 \mathrm{~m}$ from the reef horizon and the sub-shafts all transverse the reef. Three major geological structures are prevalent in the shaft pillar with displacement of up to $70 \mathrm{~m}$. In addition, numerous critical excavations are situated in close proximity either to the reef horizon or to the aforementioned geological structures.

Stress, host rock conditions and the response of the host rock to mining are at its worst during the extraction of the shaft pillar - especially at depth. Seismicity associated with the mining extraction and major geological structures increases the risk to workers and the integrity of critical excavations. This paper attempts to evaluate the seismic potential when extracting the shaft pillar through the process of correlating of numerical modelling and seismic monitoring of other similar highly stressed areas on the mine.

\section{INTRODUCTION}

Kloof Gold Mine is situated West of Johannesburg within "THE GOLDEN ARC" which stretches for 300 kilometres east and west of Johannesburg and south into the Orange Free State.

\section{THE GOLDEN ARC}

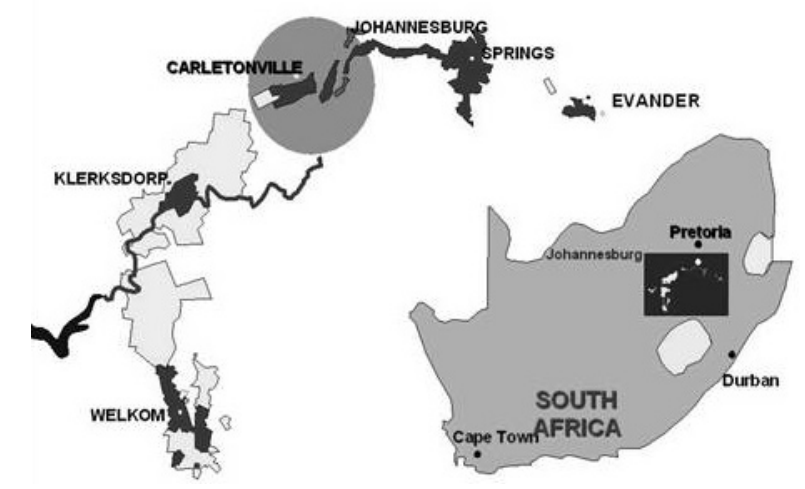

FIG. 1 The position of Kloof Gold Mines within "The Golden Arc"

On all of the shafts, the primary reef horizon is the Ventersdorp Contact Reef (VCR). The VCR consists of conglomerates (erosion debris) and interbedded quartzite varying in overall thickness from a single pebble layer to composite "zones" of about three metres in width.

The Kloof Main Shaft Complex (No. 1 shaft) is mining at a depth of between 2000 and $3000 \mathrm{~m}$ below surface at an average stoping width of $1.5 \mathrm{~m}$. Extensive mining has taken place from the three shafts within the complex. The three shafts are the surface or main shaft that stretches from surface to a depth of 2023 metres. The 1 sub-vertical shaft extends to 2773 metres below surface and the No. 2 sub-vertical shaft extends to a depth of 3306 metres below surface.

Longwall mining forms the primary mining method from these shafts. Due to the extent of extraction, mining is currently concentrated around pillars and the mining of the

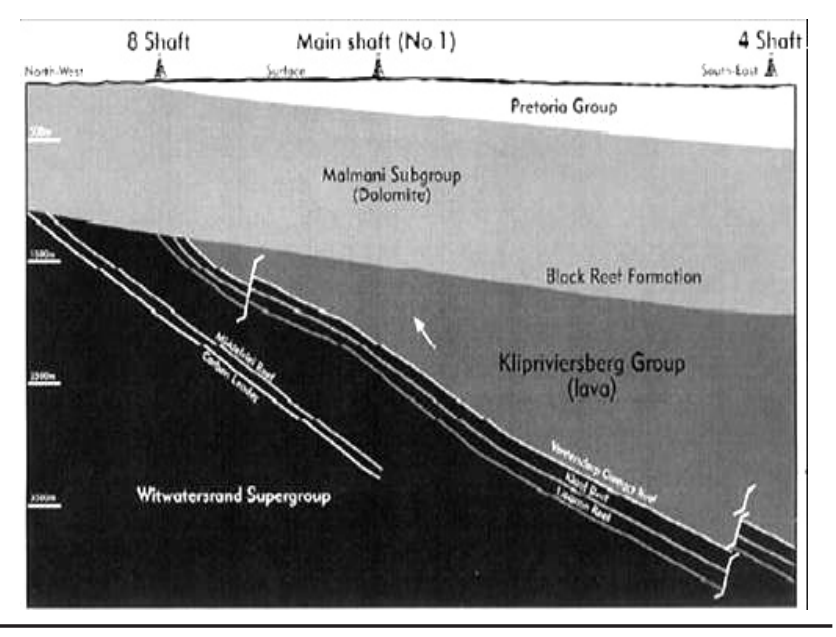

FIG. 2 Cross-section of the geology on Kloof Gold Mine

final remnant between approaching longwalls. This type of mining is usually associated with higher levels of stress, higher energy release rate (ERR) and increased seismicity.

These three shafts are protected by a semi-rectangular pillar of dimensions 670 metres on strike and $970 \mathrm{~m}$ on dip. Significant ore-reserves are available within this shaft pillar. Mining of the shaft pillar is planned to start by the year 2007. The shafts must remain operational, especially the surface shaft, after the extraction of the shaft pillar as the infrastructure and services such as pumping and hoisting is required for the other shafts within the Kloof Division. The sub-vertical shafts must remain operational for secondary reef mining as well as pillar mining.

It is common knowledge that mining of the shaft pillar is associated with high stress conditions and the presence of major geological structures increases the hazard (seismic) associated with the extraction of the pillar. The Main shaft pillar is intersected by three major geological structures, the Venterspost dyke, the Tear Fault and an offshoot of the Tear Fault. Both the Tear Fault and the offshoot are known to consist of Dyke material. 


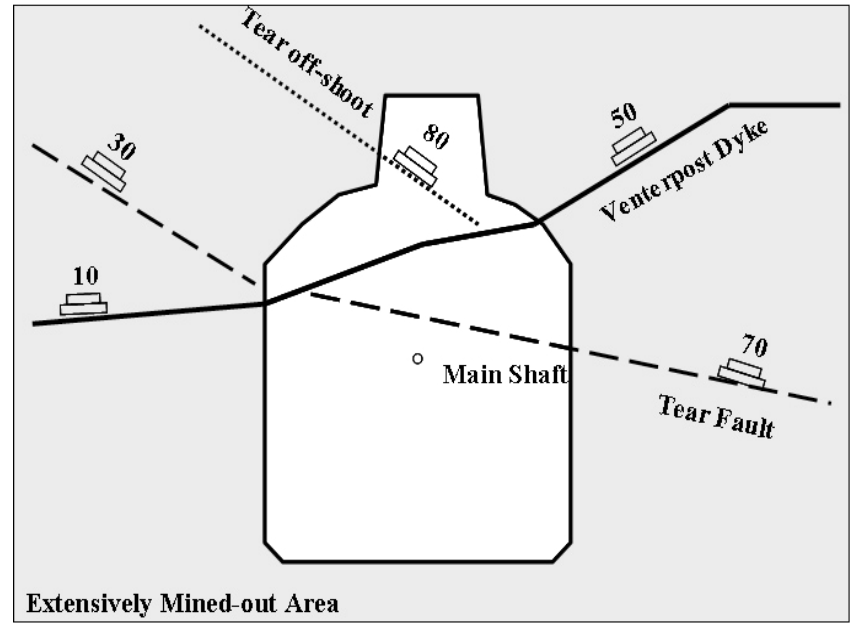

FIG. 3 Kloof Main Shaft Complex - shaft pillar and associated major geological structures

This paper describes the method of assessing the seismic hazard associated with the extraction of the shaft pillar. It is based on the SIMRAC project work done by ISS International entitled "Methods to Assess Seismic Hazards in South African Gold Mines" which inturn in based on the outcomes to two particular SIMRAC projects, GAP 605 (van Aswegen, 2002) and 612a (Lachenicht, 2001).

The method is based on the correlation of seismic data with "static" numerical modelling. The seismic data was obtained from the Kloof digital Integrated Seismic System (ISS) and the numerical modelling results were obtained through the use of the modelling package, MAP3D.

\section{METHODOLOGY}

As described by (Sanopoulos and van Aswegen, 2001), the primary objective is to establish an empirical relationship between modelled stability parameters and observed seismic response to mining through various mining steps (time) in a particular mining area. Modelling base parameters are maintained throughout the analysis and hence for the empirical relationship. The closer the initial model parameter assumptions are to reality, the better the final empirical correlation will be. However, due to the empirical nature of the method, highly accurate initial parameter assumptions are not vital.

The empirical correlation between the modelled and observed data provides a practical tool for the estimation of the seismic hazard associated with long term planned mining layouts.

Once the empirical relationships between the model stability parameters and the historic seismicity are developed, these empirical relationships are then applied to the seismic hazard assessment of future planned mining layouts.

This paper will deal with two methods of assessing seismic hazard associated with the extraction of the shaft pillar. These are:

- The assessment of the seismic hazard associated with the mine layout and;

- The assessment of the seismic hazard associated with major geological structures.

\section{ASSESSMENT METHODS}

\subsection{Mine Layout Assessment}

For mine layout assessment, the method is based on the modelled Volumetric Energy Release (VER) and the calibration of seismic data for the various mining steps. VER is equivalent to the model parameter Wk, a subset of LERD (Wiles, 1998). It represents the energy stored in the "mined volume". The maximum amount of energy that can be released as kinetic energy is the area of the upper triangle in Figure 4.

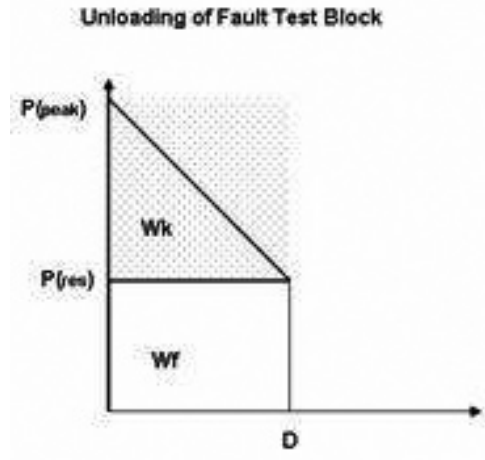

Wh Maximum amount of energy released as kinetic energy [MJ]

Wt. Manimum amount of energy dissipased from frictional deformation (MJ)

Unloading of test block [MN]

D : Total detormation of test block associated weth unbeding [m]

FIG. 4 Load-deformation diagram showing the model parameters Wk (Wiles, 1998)

VER (Wk) is directly calculated in Map3D. The important aspects of VER are:

- It is this measure of the loading system stiffness that corresponds to the $m_{\max }$ of the measured frequency magnitude relation and hence is representative of the seismic hazard (Gap612a).

- VER is not normalised by the volume mined, but represents the highest amount of energy stored in that volume during that time period.

- VER is calculated through a set modelling procedure independent of scale. Hence VER can be applied to the statistical correlation of large amounts of seismic data from variable sized areas.

\subsection{Geological Structures Assessment}

The assessment of seismic hazard associated with geological structures will be based on the concept of Excess Shear Stress (ESS) (as described by Ryder, 1988) where the modelling attempts to measure the driving shear stress on a plane of weakness.

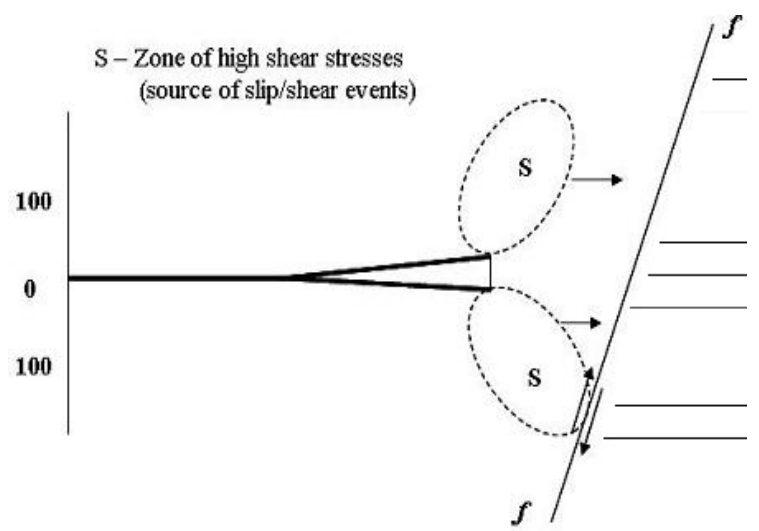

FIG. 5 Mining induced shear stresses (ESS) triggering seismic events (Ryder and Jager, 2002) 
The lack of reliable seismic data (described further in this paper) for the shaft pillar makes calibration of seismic data with modelled stability parameters for the geological structures difficult. The response of the various structures to mining is different due to their different geometry and material properties as well as their position relative to the mining. For this reason, taking calibrated data from similar mining areas (indicated in the assessment of the mine layout) would not be appropriate to assess the seismic hazard associated with the geological structures within the shaft pillar area. ESS modelling will estimate the upper bound of magnitude when mining close to geological structures as well as the impact of regional support and the impact of changing mining layouts. [Note, the last two assessments will not form part of this paper but will be mentioned].

\section{MAIN SHAFT PILLAR EXTRACTION MODEL (MAP3D)}

A Map3D model was built in accordance with the planned extraction sequence derived through the numerical modelling assessment of the stability of the shaft infrastructure and critical excavations.

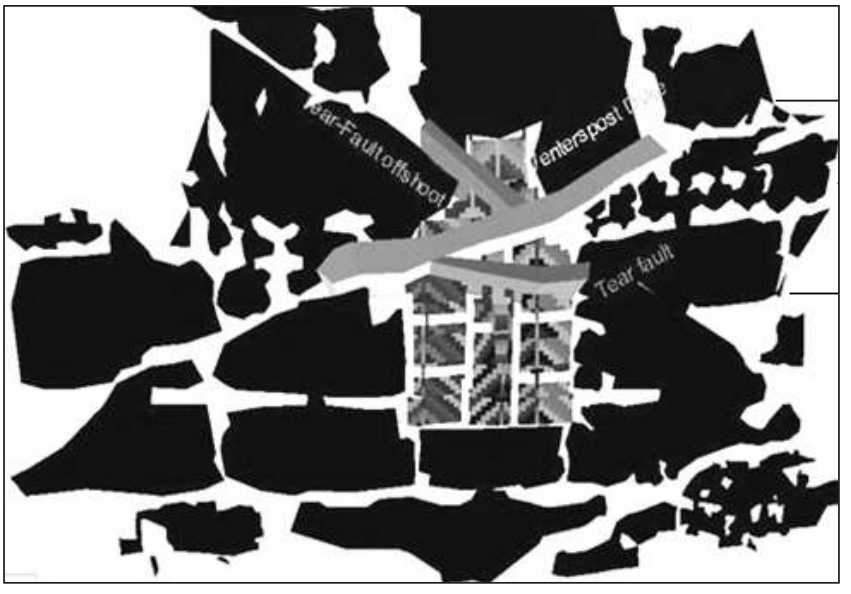

FIG. 6 Plan view of main shaft pillar area showing the extraction sequence and geological structures

The following modelling parameters were used:

Rockmass properties:

- Host rock is an elastic medium

- Young's modulus: $60 \mathrm{GPa}$

- Poisons ratio: 0.2

- K-ratio: 0.5

Structural properties:

- Friction angle $\phi=30^{\circ}$

- Young's modulus E = $60 \mathrm{GPa}$

- Poisson's ratio $\mathrm{v}=0.2$

\section{CALIBRATION OF MODELLED STABILITY PARAMETERS (VER) AND RECORDED SEISMICITY FOR THE MAIN SHAFT PILLAR}

In order to assess the seismic hazard for the planned extraction sequence of the shaft pillar, a correlation between the modelled stability parameters i.e. VER and the recorded seismicity must be determined. Mining done to define the shaft pillar was done prior to the installation of the current digital integrated seismic system (ISS). Seismic events associated with mining in the vicinity of the shaft pillar were recorded from the previous centralised analogue seismic system. There was substantial variation in sensitivity, location accuracy and source parameter calculations between the two systems.
Based on the above, as well as the fact that detailed phase mining of areas around the shaft pillar could not be acquired, correlation between recorded seismicity and modelled stability parameters could not be determined with any accuracy.

In order to establish a more reliable correlation method, an area of similar geo-technical makeup and stress environment was chosen to determine a correlation between the recorded seismic events (from the digital integrated seismic system) and modelled stability parameters (from detailed plans showing the mining sequence). This empirical relationship will be applied to the modelled VER obtained from the planned mining sequence of the shaft pillar. The area chosen was the $36-39 / 34 \mathrm{~S}$ working areas.

\section{CALIBRATION OF MODELLED STABILITY PARAMETERS (VER) AND RECORDED SEISMICITY FOR THE 36-39/34 S WORKING AREA}

The 36-39/34 S area was chosen since the final stages of mining in this area was done under increased stress conditions due to the extensive mining around the area of interest. It is assumed that the seismic response to mining at the 36$39 / 34 \mathrm{~S}$ would simulate, to a certain degree of accuracy, the expected response of mining taking place within the shaft pillar since the ground conditions are similar.

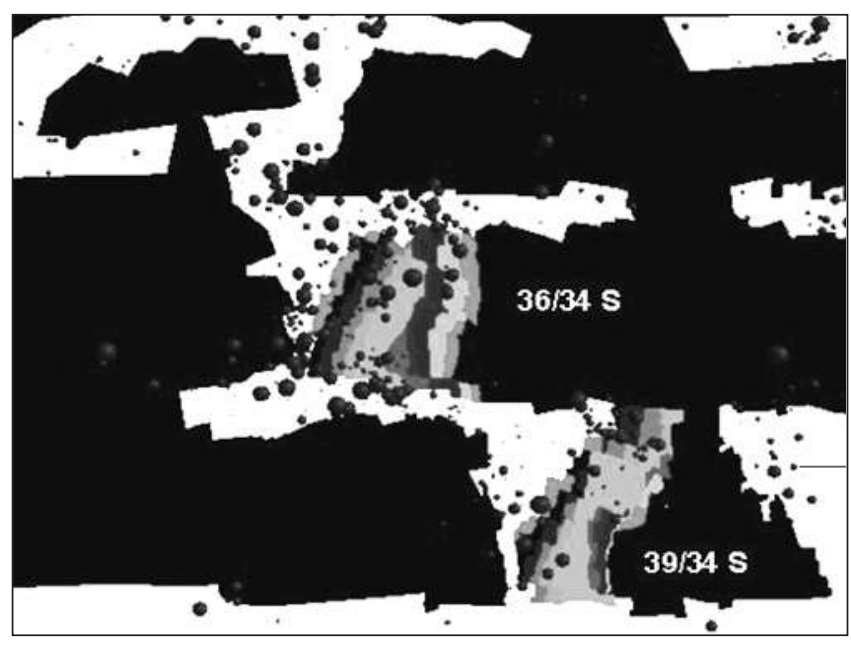

FIG. 7 Plan view of the 36-39/34 S area showing the extraction sequence and recorded seismic events

In determining the seismic hazard associated with the mining layout, difficulty arises in separating those events that are related to the volume extracted and those related to slip on geological structures. Experience has shown that the large events are almost common to known geological structures. The "Code of Practice (COP) to Combat Rockfall and Rockburst Accidents" for Kloof Gold Mine attempts to determine the sources of seismic emissions based on locations of the events. Almost all events greater than local magnitude 2.0 are structural related. Seismic events of local magnitude less than 2.0 are predominantly associated with the mining face as indicated in the COP. For the purpose of this analysis, it is a fair assumption that events of magnitude less than 2.0 would be associated with the mining face and these would be used in the correlation of the seismic data with modelled stability parameters (VER).

\subsection{Modelled VER and Seismic Data}

The table below summarises the results based on the modelled VER and recorded seismic parameter, $\Sigma$ Mo. The mining steps are in quarterly ( 3 monthly) intervals except mining step 7 , which constitutes 3 quarters data. 
TABLE 1 Modelled VER and $\Sigma$ Mo for various mining steps

\begin{tabular}{|c|c|c|c|c|}
\hline Step & Date & Area & VER & $\Sigma \mathrm{Mo}$ \\
\hline 2 & 11'99 - 02'00 & 5494 & $2.02 E+05$ & $8.32 E+12$ \\
\hline 3 & $02 ' 00$ - 5’00 & 7747 & $2.69 E+05$ & $6.55 E+12$ \\
\hline 4 & 5'00 - 08'00 & 6385 & 1.95E+05 & $7.82 E+12$ \\
\hline 5 & 08 '00 - 11'00 & 3570 & $1.34 \mathrm{E}+05$ & $1.63 \mathrm{E}+13$ \\
\hline 6 & $11^{\prime} 00-02 ' 01$ & 3280 & $1.15 E+05$ & $1.03 E+13$ \\
\hline 7 & $02 ' 01-11^{\prime} 01$ & 21000 & $6.61 E+05$ & $4.55 E+13$ \\
\hline 8 & $11^{\prime} 01-02$ '02 & 6735 & $2.76 \mathrm{E}+05$ & $1.03 E+13$ \\
\hline 9 & $02{ }^{\prime} 02-05^{\prime} 02$ & 7697 & $3.75 E+05$ & $2.33 E+13$ \\
\hline 10 & $05^{\prime} 02$ - 08'02 & 7655 & $4.02 \mathrm{E}+05$ & $2.50 \mathrm{E}+13$ \\
\hline 11 & 08 '02 - 11'02 & 7365 & $3.08 E+05$ & $9.25 E+12$ \\
\hline 12 & $11^{\prime} 02-02$ '03 & 6101 & $2.75 E+05$ & $9.18 \mathrm{E}+12$ \\
\hline
\end{tabular}

Figures 8 and 9 show the correlation between VER and $\Sigma$ Mo for each individual step.

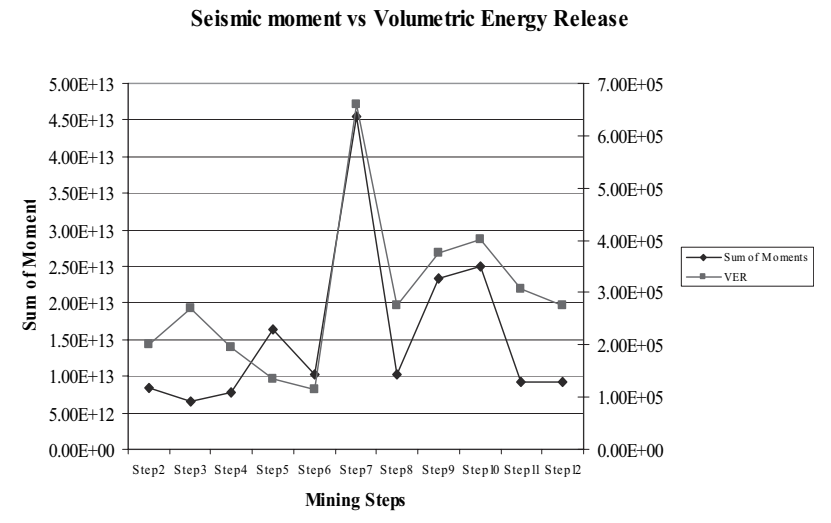

FIG. 8 VER and $\Sigma$ Mo per mining step

\section{X-Y plot of Sum Mo and VER}

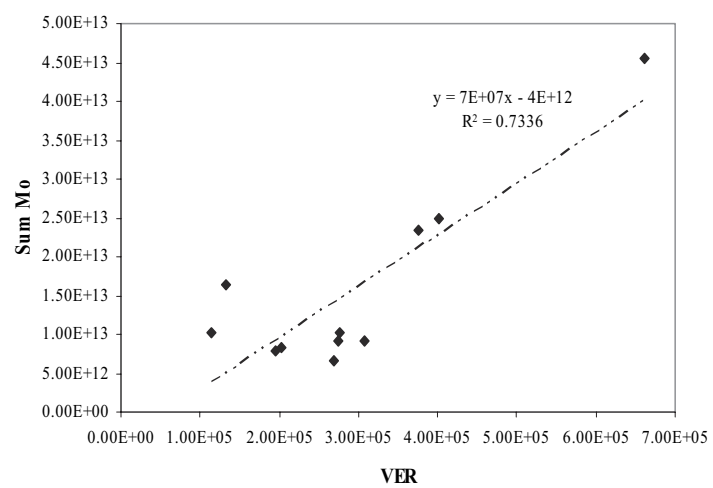

FIG. 9 Scatter-plot to compare VER and $\Sigma$ Mo correlation coefficient 0.86

A fairly good correlation between VER and $\Sigma$ Mo is achieved. However, two data points appears to be inconsistent with the others. These are step 5 and step 6 . The exclusion of step 5 and 6 from the comparison highlights a far better correlation between modelled VER and $\Sigma \mathrm{Mo}$.

\subsection{History of the 36/34 S Mining Area}

Two large structural seismic events (local magnitudes 3.1 and 2.9) occurred on 22 September 2000. These events caused extensive damage to the panels along the 36/34 S mining area. These events also caused injuries to numerous workers at the time.
Seismic moment vs Volumetric Energy Release

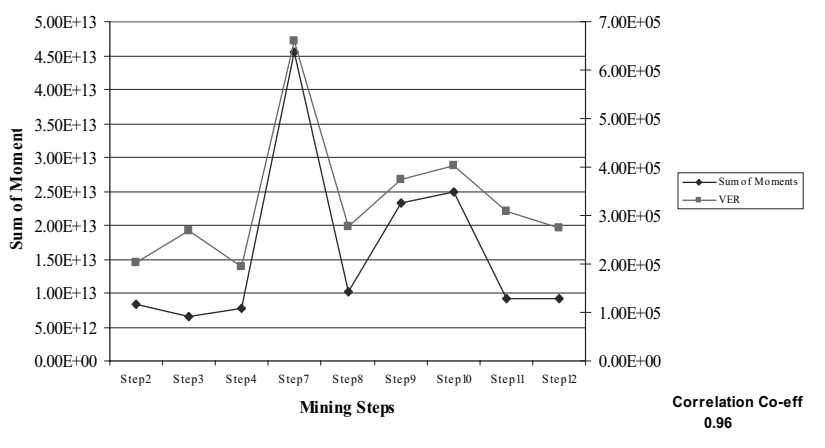

FIG. 10 VER and $\Sigma M o$ (excluding steps 5 and 6 )

X-Y plot of Sum Mo and VER

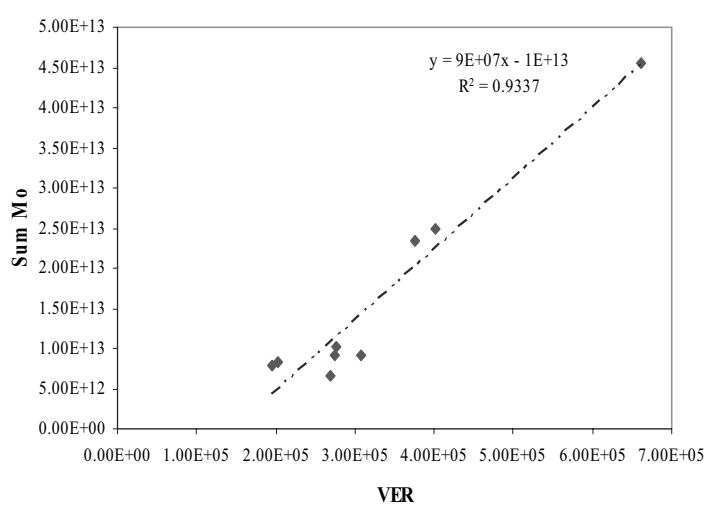

FIG. 11 Scatter-plot to compare VER and $\Sigma$ Mo correlation coefficient 0.96

A decision was taken to stop mining at the $36 / 34$ S until all the appropriate steps were in place to address the hazards associated with mining this highly stressed area. The two quarters (steps 5 and 6), August 2000 to February 2001, experience much lower production results as a consequence of the problems experienced at 36/34 S. Although mining continued at $39 / 34 \mathrm{~S}$, the production from the area was nearly half of that recorded during normal production quarters as illustrated in table 1 . The seismic events that were recorded during these two quarters were predominantly associated with the abutments of the strike stabilizing pillars and very few events were located on the mining faces that ultimately would have an effect on the correlation of modelled VER and recorded Seismic Moment.

Based on the abnormal occurrence experienced during step 5 and 6 , the exclusion of these two steps from the model calibration can be justified. Once mining returned to normal production, the model calibration became more consistent.

\section{CALCULATION OF THE EXPECTED SEISMICITY FOR THE PLANNED EXTRACTION OF THE MAIN SHAFT PILLAR BASED ON CALIBRATION RESULTS OF 36-39/34 MINING AREA}

\subsection{Calculation of Expected Seismicity}

Results from the 36-39/34 S mining area indicate a good correlation between modelled VER and $\Sigma$ Mo for each individual mining step. A correlation co-efficient of 0.96 was calculated. The relationship between modelled VER and seismic moment for each step is given by the formula:

$$
\text { Seismic Moment }=9 \mathrm{e} 07 \text { * }(\text { VER })-1 \mathrm{e} 13
$$




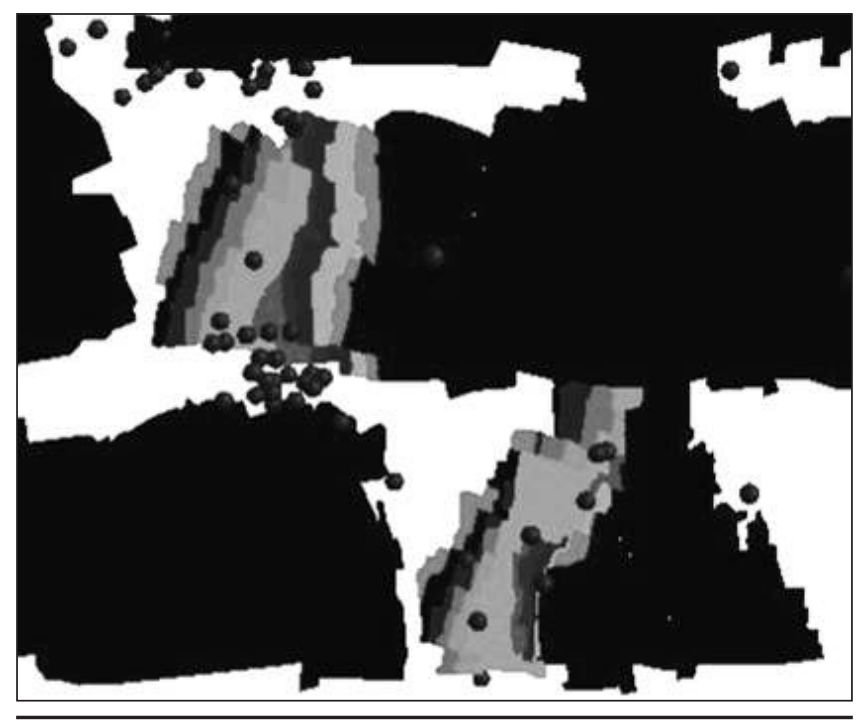

FIG. 12 Location of recorded events during mining steps 5 and 6

Applying this formula to the modelled VER for the shaft pillar, results in the following expected seismic moment for each individual step. The period of each mining step is based on the planned extraction of $6000 \mathrm{~m}^{2}$ per month.

TABLE 2 Calculated expected $\Sigma$ Mo for the sequence of mining within the shaft pillar

\begin{tabular}{lcccc}
\hline Step & $\begin{array}{c}\text { Period } \\
\text { Months }\end{array}$ & Area Mined & VER & $\begin{array}{c}\Sigma \text { Mo } \\
\text { (Expected) }\end{array}$ \\
\hline 3 & 3.05 & 18298.21 & $5.57 \mathrm{E}+04$ & - \\
4 & 2.91 & 17486.93 & $7.22 \mathrm{E}+04$ & - \\
5 & 2.87 & 17201.97 & $7.44 \mathrm{E}+04$ & - \\
6 & 2.41 & 14475.84 & $1.20 \mathrm{E}+05$ & $8.00 \mathrm{E}+11$ \\
7 & 2.86 & 17180.32 & $1.40 \mathrm{E}+05$ & $2.62 \mathrm{E}+12$ \\
8 & 3.13 & 18788.95 & $2.57 \mathrm{E}+05$ & $1.32 \mathrm{E}+13$ \\
9 & 3.07 & 18440.11 & $2.20 \mathrm{E}+05$ & $9.84 \mathrm{E}+12$ \\
10 & 4.87 & 29193.33 & $2.08 \mathrm{E}+05$ & $8.74 \mathrm{E}+12$ \\
11 & 4.61 & 27677.34 & $2.08 \mathrm{E}+05$ & $8.76 \mathrm{E}+12$ \\
12 & 3.31 & 19846.67 & $1.59 \mathrm{E}+05$ & $4.32 \mathrm{E}+12$ \\
13 & 3.79 & 22760.29 & $2.59 \mathrm{E}+05$ & $1.33 \mathrm{E}+13$ \\
14 & 3.38 & 20273.98 & $2.14 \mathrm{E}+05$ & $9.25 \mathrm{E}+12$ \\
15 & 4.02 & 24126.65 & $2.27 \mathrm{E}+05$ & $1.04 \mathrm{E}+13$ \\
16 & 3.27 & 19592.36 & $2.14 \mathrm{E}+05$ & $9.25 \mathrm{E}+12$ \\
17 & 2.60 & 15601.18 & $2.32 \mathrm{E}+05$ & $1.09 \mathrm{E}+13$ \\
18 & 2.89 & 17353.23 & $2.77 \mathrm{E}+05$ & $1.49 \mathrm{E}+13$ \\
19 & 3.37 & 20225.02 & $2.94 \mathrm{E}+05$ & $1.65 \mathrm{E}+13$ \\
20 & 3.25 & 19470.89 & $3.19 \mathrm{E}+05$ & $1.87 \mathrm{E}+13$ \\
21 & 2.47 & 14831.82 & $3.24 \mathrm{E}+05$ & $1.92 \mathrm{E}+13$ \\
22 & 2.47 & 14821.58 & $3.03 \mathrm{E}+05$ & $1.73 \mathrm{E}+13$ \\
23 & 4.44 & 26655.89 & $6.77 \mathrm{E}+05$ & $5.09 \mathrm{E}+13$ \\
24 & 1.87 & 11212.36 & $3.51 \mathrm{E}+05$ & $2.16 \mathrm{E}+13$ \\
\hline & & & &
\end{tabular}

The first three steps would represent the initial inner-cut mining around the 3 shafts. The stress state during this time is considered much lower than that experienced at the calibration site (36-39/34 S working area). Thus no seismic moment was calculated during these initial mining steps.

\subsection{Seismic Distribution}

On a mineshaft, the concepts of seismic moment and seismic energy are not well understood or comprehended. Mine workers are very much aware of the concept of magnitude as a description of the intensity of the seismic event. This is based on their knowledge of seismic related damage. It is thus important to interpret the expected seismic moment as a distribution of seismic events within various magnitude ranges.

In order to do this, the following methodology was adopted:

Determine whether a correlation exist between VER and the number of events greater and equal to 0.0

$[\mathrm{N}(>=0.0)]$ for mining area 36-39/34S.

Calculate expected $\mathrm{N}(>=0.0)$ for the shaft pillar area based on the correlation.

Calculate the historic $b$-value for the mining of the 36-39/34 S area.

Determine the distribution of events based on the Gutenberg-Richter relationship,

$$
\log N=a-b M
$$

N (>=0.0) vs Volumetric Energy Release

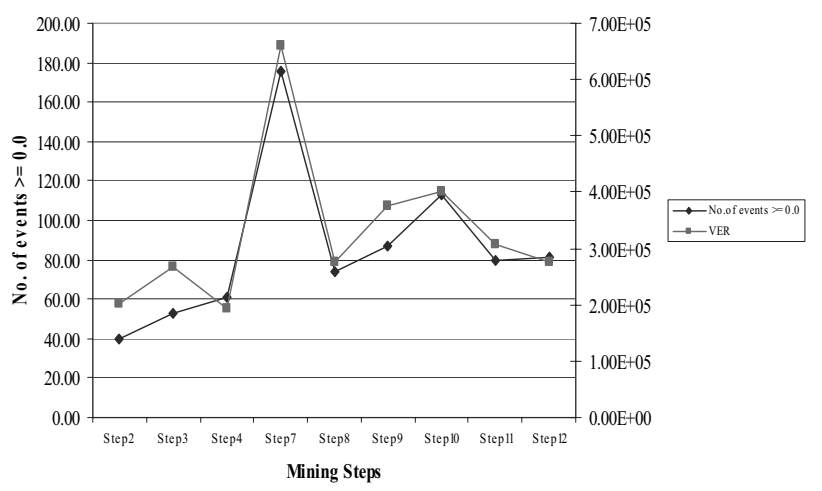

FIG. 13 VER and $\mathrm{N}(>=0.0)$ for the $36-39 / 34 \mathrm{~S}$ working areas

$\mathrm{X}-\mathrm{Y}$ plot of $\mathrm{N}(>=0.0)$ and VER

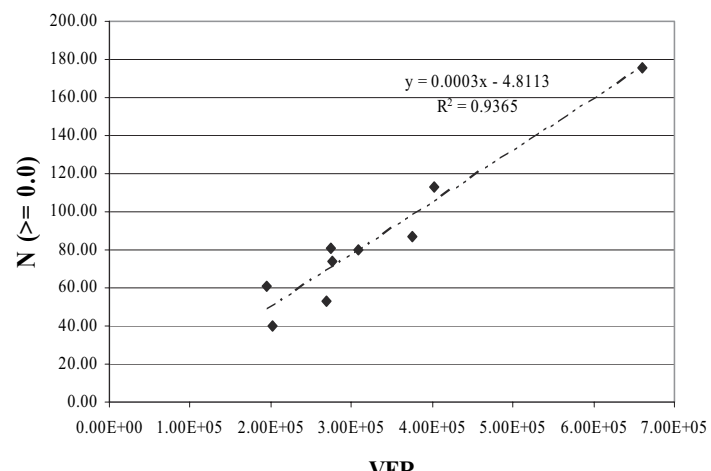

VER

FIG. 14 Scatter-plot of VER and N $(>=0.0)$ for the $36-39 / 34 \mathrm{~S}$ working areas - correlation co-efficient 0.97

A correlation co-efficient of 0.97 would suggest that a good link exist between VER and the number of events greater than and equal to 0.0 for the $36-39 / 34 \mathrm{~S}$ working area. The number of events greater than and equal to 0.0 for each individual mining step within the shaft pillar can be calculated from the equation:

$$
N(>=0.0)=0.0003 \text { *VER }-4.8113
$$


The b-value which describes the slope of the GutenbergRichter for the historical data of the 36-39/34 working area was calculated 0.81 .

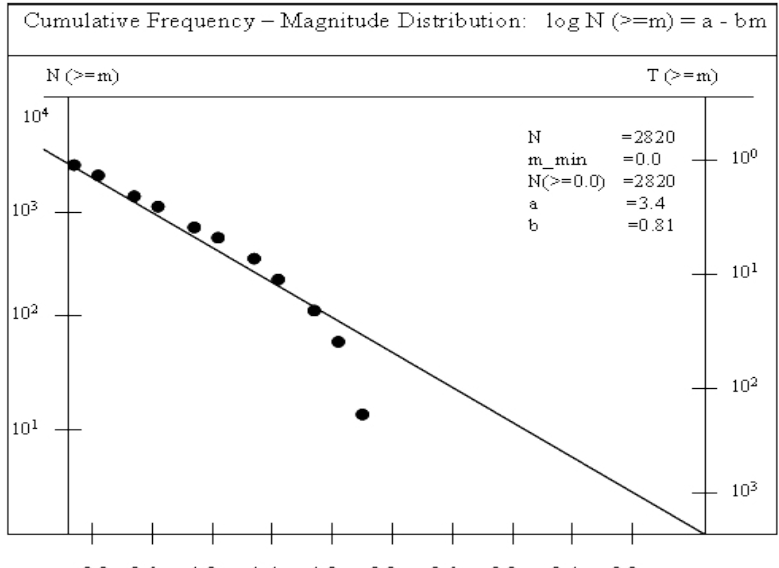

$\begin{array}{llllllllll}0.2 & 0.6 & 1.0 & 1.4 & 1.8 & 2.2 & 2.6 & 3.0 & 3.4 & 3.8\end{array}$

FIG. 15 Cumulative-Frequency-Magnitude distribution for the $36-39 / 34 \mathrm{~S}$ working areas

From equation $3, \mathrm{~N}(>=0.0)$ can be calculated for the shaft pillar extraction. This together with the anticipated b-value will generate a distribution of seismic events within the various magnitude ranges calculated from equation [2]:

TABLE 3 Calculated seismic distributions for the sequence of mining within the shaft pillar

\begin{tabular}{lcccccc}
\hline Step & VER & $\mathbf{N}$ & $\mathbf{M}>\mathbf{0}$ & $\mathbf{M}>\mathbf{1}$ & $\mathbf{M}>\mathbf{2}$ & $\mathbf{M}>\mathbf{3}$ \\
\hline 3 & $5.57 \mathrm{E}+04$ & & & & & \\
4 & $7.22 \mathrm{E}+04$ & & & & & \\
5 & $7.44 \mathrm{E}+04$ & & & & & \\
6 & $1.20 \mathrm{E}+05$ & 31 & 31 & 5 & 1 & 0 \\
7 & $1.40 \mathrm{E}+05$ & 37 & 37 & 6 & 1 & 0 \\
8 & $2.57 \mathrm{E}+05$ & 72 & 72 & 11 & 2 & 0 \\
9 & $2.20 \mathrm{E}+05$ & 61 & 61 & 9 & 1 & 0 \\
10 & $2.08 \mathrm{E}+05$ & 58 & 58 & 9 & 1 & 0 \\
11 & $2.08 \mathrm{E}+05$ & 58 & 58 & 9 & 1 & 0 \\
12 & $1.59 \mathrm{E}+05$ & 43 & 43 & 7 & 1 & 0 \\
13 & $2.59 \mathrm{E}+05$ & 73 & 73 & 11 & 2 & 0 \\
14 & $2.14 \mathrm{E}+05$ & 59 & 59 & 9 & 1 & 0 \\
15 & $2.27 \mathrm{E}+05$ & 63 & 63 & 10 & 2 & 0 \\
16 & $2.14 \mathrm{E}+05$ & 59 & 59 & 9 & 1 & 0 \\
17 & $2.32 \mathrm{E}+05$ & 65 & 65 & 10 & 2 & 0 \\
18 & $2.77 \mathrm{E}+05$ & 78 & 78 & 12 & 2 & 0 \\
19 & $2.94 \mathrm{E}+05$ & 84 & 84 & 13 & 2 & 0 \\
20 & $3.19 \mathrm{E}+05$ & 91 & 91 & 14 & 2 & 0 \\
21 & $3.24 \mathrm{E}+05$ & 92 & 92 & 14 & 2 & 0 \\
22 & $3.03 \mathrm{E}+05$ & 86 & 86 & 13 & 2 & 0 \\
23 & $6.77 \mathrm{E}+05$ & 198 & 198 & 31 & 5 & 1 \\
24 & $3.51 \mathrm{E}+05$ & 100 & 100 & 15 & 2 & 0 \\
\hline
\end{tabular}

Table 3 highlights the importance of assessing the seismic hazard associated with the extraction sequence prior to the mining of the shaft pillar. What is important is to identify those steps in which there are a dramatic change in the VER and ultimately the seismic hazard. An example of this is mining step 23 which shows a dramatic increase in the number of events.

\section{ASSESSMENT OF THE SEISMIC HAZARD ASSOCIATED WITH THE GEOLOGICAL STRUCTURES}

Excess Shear Stress (ESS $\left.=\tau-\mu \sigma_{n}\right)$ modelling identifies lobes of positive ESS on the geological structures that would signify potential instability. The expected magnitude can be calculated based on the size of the positive ESS lobes.

\subsection{Calculation of Seismic Moment}

The relationship between ESS and seismic moment has been investigated for many years. The relationship as suggested by Ryder, (1988), calculates Moment as:

$$
\text { Moment }=2 * a^{2 *} \mathrm{I} \text { * Te }
$$

Where, "a" is the half width of the positive ESS lobes, 1 is the length of positive ESS lobes and Te is the maximum positive ESS value.

\subsection{Calculation of Richter Magnitude}

The relationship between moment and Richter magnitude is given by Ryder as:

$$
\text { Magnitude }=2 / 3 \text { * Log Moment }-2.1
$$

\subsection{Estimating the Upper-Bound of Magnitude for Structural Seismic Events within the Shaft Pillar}

Grids were placed depicting the three major geological structures namely Venterspost Dyke, Tear Fault and Tear Fault offshoot. Bracket pillars of $20 \mathrm{~m}$ wide on either side of these structures were placed to act as partial barriers against seismic activity. Due to mining constraints, wide raises are taken through some of these structures in places.

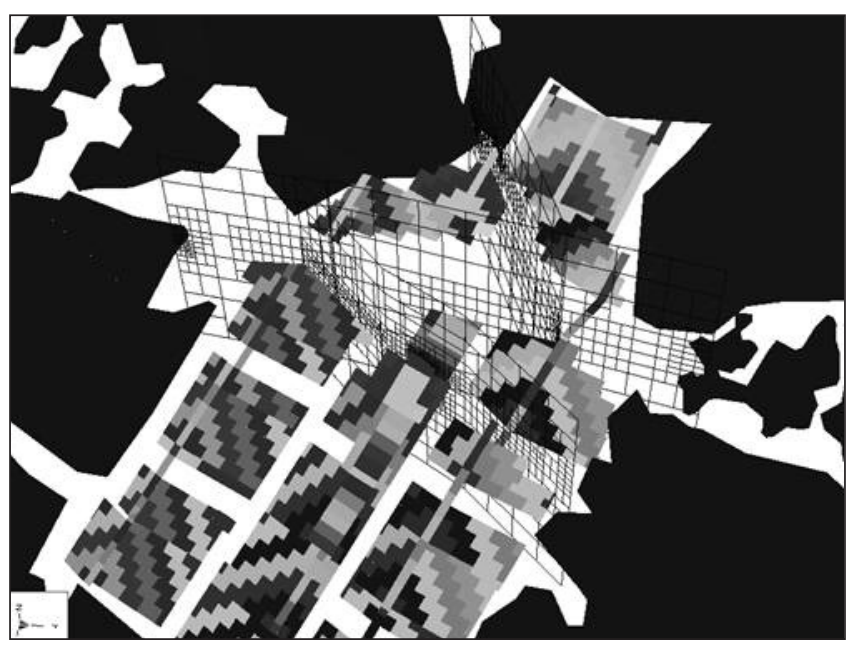

FIG. 16 Grids depicting geological structures on which ESS will be calculated

The seismic moment was calculated as well as the expected magnitude per mining step for the various geological structures and is summarise in Tables 4,5 and 6 . 


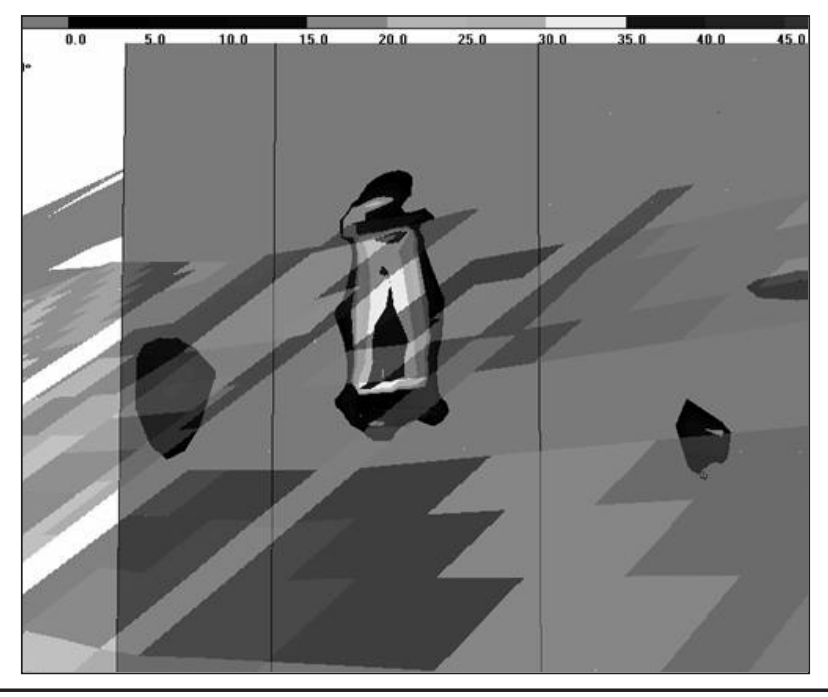

FIG. 17 Lobes of positive ESS on Tear Fault

TABLE 4 Calculated seismic moment and expected magnitude for the Venterspost Dyke

\begin{tabular}{lll}
\hline Step & Venterspost Dyke & \\
& $\mathrm{M}_{\circ}$ & Magnitude \\
\hline 4 & $6.6 \mathrm{E}+04$ & 1.5 \\
5 & $2.7 \mathrm{E}+05$ & 2.0 \\
6 & $2.0 \mathrm{E}+05$ & 1.9 \\
7 & $2.2 \mathrm{E}+05$ & 1.9 \\
8 & $2.4 \mathrm{E}+05$ & 1.9 \\
9 & $3.7 \mathrm{E}+05$ & 2.1 \\
10 & $3.3 \mathrm{E}+05$ & 2.0 \\
11 & $3.6 \mathrm{E}+05$ & 2.1 \\
12 & $3.7 \mathrm{E}+05$ & 2.1 \\
13 & $3.8 \mathrm{E}+05$ & 2.1 \\
14 & $4.6 \mathrm{E}+05$ & 2.1 \\
15 & $4.1 \mathrm{E}+05$ & 2.1 \\
16 & $3.9 \mathrm{E}+05$ & 2.1 \\
17 & $4.3 \mathrm{E}+05$ & 2.1 \\
18 & $4.3 \mathrm{E}+05$ & 2.1 \\
19 & $4.3 \mathrm{E}+05$ & 2.1 \\
20 & $4.3 \mathrm{E}+05$ & 2.1 \\
21 & $4.3 \mathrm{E}+05$ & 2.1 \\
22 & $4.4 \mathrm{E}+05$ & 2.1 \\
23 & $4.4 \mathrm{E}+05$ & 2.1 \\
24 & $4.4 \mathrm{E}+05$ & 2.1 \\
\hline
\end{tabular}

TABLE 5 Calculated seismic moment and expected magnitude for the Tear Fault

\begin{tabular}{lcc}
\hline Step & \multicolumn{2}{c}{ Tear Fault } \\
& $\mathrm{M}_{\circ}$ & Magnitude \\
\hline 3 & & \\
4 & $3.7 \mathrm{E}+06$ & 2.8 \\
5 & $7.6 \mathrm{E}+06$ & 3.1 \\
6 & $8.0 \mathrm{E}+06$ & 3.1 \\
7 & $8.7 \mathrm{E}+06$ & 3.1 \\
8 & $8.8 \mathrm{E}+06$ & 3.1 \\
9 & $9.9 \mathrm{E}+06$ & 3.1 \\
10 & $9.9 \mathrm{E}+06$ & 3.1 \\
11 & $9.9 \mathrm{E}+06$ & 3.1 \\
12 & $1.0 \mathrm{E}+07$ & 3.1 \\
13 & $9.5 \mathrm{E}+06$ & 3.1 \\
14 & $9.7 \mathrm{E}+06$ & 3.1 \\
15 & $9.7 \mathrm{E}+06$ & 3.1 \\
16 & $9.8 \mathrm{E}+06$ & 3.1 \\
17 & $9.8 \mathrm{E}+06$ & 3.1 \\
18 & $1.0 \mathrm{E}+07$ & 3.1 \\
19 & $1.0 \mathrm{E}+07$ & 3.1 \\
20 & $1.0 \mathrm{E}+07$ & 3.1 \\
21 & $1.0 \mathrm{E}+07$ & 3.2 \\
22 & $1.0 \mathrm{E}+07$ & 3.2 \\
23 & $1.0 \mathrm{E}+07$ & 3.2 \\
24 & $1.1 \mathrm{E}+07$ & 3.2 \\
\hline
\end{tabular}

TABLE 6 Calculated seismic moment and expected magnitude for the Tear Fault Off-Shoot

\begin{tabular}{lcc}
\hline Step & \multicolumn{2}{c}{ Tear Fault Off-Shoot } \\
& $\mathrm{M}_{\circ}$ & Magnitude \\
\hline 3 & $5.0 \mathrm{E}+04$ & 1.42 \\
4 & $6.5 \mathrm{E}+04$ & 1.51 \\
5 & $7.0 \mathrm{E}+04$ & 1.54 \\
6 & $7.6 \mathrm{E}+04$ & 1.56 \\
7 & $1.4 \mathrm{E}+05$ & 1.77 \\
8 & $2.5 \mathrm{E}+05$ & 1.95 \\
9 & $2.6 \mathrm{E}+05$ & 1.96 \\
10 & $2.9 \mathrm{E}+05$ & 2.00 \\
11 & $2.9 \mathrm{E}+05$ & 2.00 \\
12 & $2.9 \mathrm{E}+05$ & 2.00 \\
13 & $3.0 \mathrm{E}+05$ & 2.01 \\
14 & $3.0 \mathrm{E}+05$ & 2.01 \\
15 & $2.6 \mathrm{E}+05$ & 1.96 \\
16 & $2.6 \mathrm{E}+05$ & 1.96 \\
17 & $2.6 \mathrm{E}+05$ & 1.96 \\
18 & $2.8 \mathrm{E}+05$ & 1.98 \\
19 & $2.8 \mathrm{E}+05$ & 1.98 \\
20 & $3.2 \mathrm{E}+05$ & 2.03 \\
21 & $3.2 \mathrm{E}+05$ & 2.03 \\
22 & $3.2 \mathrm{E}+05$ & 2.03 \\
23 & $3.2 \mathrm{E}+05$ & 2.03 \\
24 & $3.2 \mathrm{E}+05$ & 2.03 \\
\hline & &
\end{tabular}


Maximum Expected Magnitude for the various Geological Structures

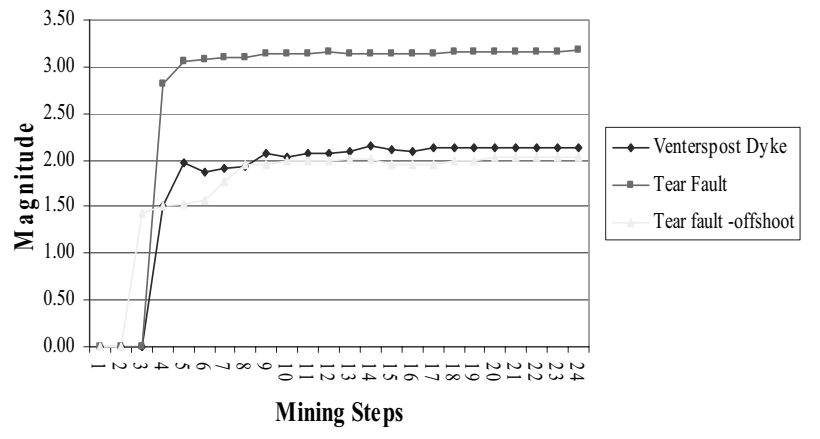

FIG. 18 Graphic representation of upper bound of magnitude for the various geological structures

The maximum possible event based on the ESS modelling is a magnitude 3.2 on the Tear fault. The Venterspost dyke and Tear Fault offshoot indicate a maximum expected magnitude of 2.1 and 2.0 respectively. The modelling indicates that the Tear Fault appears to be the most seismically hazardous structure. The biggest change in ESS is experienced when the mining (wide raises) intersect the geological structures. The inclusion of $20 \mathrm{~m}$ bracket pillars on either side of the geological structure as well as the inclusion of additional strike stabilizing pillars limits the induced seismicity associated with these structures (Mungur, 2004).

\section{CONCLUSIONS}

The main shaft complex pillar is planned to be extracted by the year 2007. The three shafts must remain operational after the extraction due to secondary reef and pillar mining as well as providing essential services to the other shafts within the Kloof Division.

The area around the shaft pillar is extensively mined and three major geological structures transect the shaft pillar. The purpose of this paper was to determine the seismic hazard associated with the extraction of the shaft pillar. The mine layout assessment was done through the calibration of seismic data and a modelled stability parameter (VER) for an area of similar geotechnical conditions.

A good correlation between VER and seismic moment was obtained, and this result was applied to the modelled shaft pillar. The end result shows a distribution of seismic events for each planned mining step.

For the geological structures, the seismic moment was determined by the size and magnitude of the positive lobes of excess shear stress modelled on grids that depicted the geological structures. ESS modelling is best used to determine the upper-bound of expected magnitude, the effects of bracket pillars to reduce the exposure of the structures to high excess shear stress and to examine the effects of alternative layouts or regional support in reducing the maximum expected magnitude.

This analysis highlighted the Tear Fault as being the geological structure that poses the highest seismic hazard. The maximum-modelled event magnitude for this feature is a 3.2.

Additional work would be required in determining the stability of the shaft infrastructure and critical excavations that would be exposed to increased levels of seismicity during the extraction of the shaft pillar. It is also imperative to continuously calibrate the model as mining progresses throughout the extraction.

\section{ACKNOWLEDGMENTS}

The author of this paper wishes to thank Gold Fields and especially the management of Kloof Gold Mine for their support in being able to publish and present this work. A special thanks to D. Geyser and N. Naicker for their encouragement and involvement in compiling this paper. In addition, the author wishes to thank $G$ van Aswegen and G Hoffmann of ISS International who provided considerable advice during the preparation of this paper.

\section{REFERENCES}

Dlokweni, T. and Lightfoot, N. (2004) Kloof 1 Shaft - Shaft Pillar Extraction Itasca Africa (Pty) Ltd. consulting report dated July 2004.

Lachenicht, R.J. (2001) Relationship between ERR, system stiffness parameters and seismic energy release for different geotechnical areas. SIMRAC Final Report GAP612a.

Mungur, G.D. (2004) An examination of the extraction of the shaft pillar on the VCR horizon - Kloof Main Shaft Complex. Internal report dated March 2004

Ryder, J.A. and Jaeger, A.J. (2002) A textbook on Rock Mechanics for Tabular Hard Rock Mines. Safety in Mines research Advisory Committee.

Ryder, J.A. (1988). Excess shear stress in the assessment of geologically hazardous situations.

J.S. Afr. Inst.Min. Metall., vol. 88 no 1.

Sanopoulos, L. and Van Aswegen, G. (2001) Mine layout design audit for rockmass stability at West-Driefontein Gold Mine No. 5 Shaft Pillar.

ISS International Mining Division, Consulting Report.

Van Aswegen, G. (2002) Analysis of the processes which leads to potentially damaging seismic events associated with geological structures and highly stressed areas in extensively mined areas and old areas SIMRAC Final Report GAP605.

Wiles, T.D. (1998) Correlation between Local Energy Release Density and observed bursting conditions at Creighton Mine. Mine Modelling Ltd: Sudbury. 